\title{
Barrio e a cooperativa Cairn ${ }^{1}$
}

\section{Barrio and Cairn Cooperative}

\section{Barrio y la cooperativa Cairn}

Viviane Matesco *
Universidade Federal Fluminense, Brasil

https://doi.org/10.22409/poiesis.v20i34.38688

RESUMO: O artigo desenvolve uma análise do Livro de Carne, trabalho do artista Arthur Barrio, focalizando o contexto parisiense onde foi criado. Examina as relações do artista com o Grupo Cairn, cooperativa de artistas atuante nos anos 1970 e verifica a proximidade entre suas ideias. A conjuntura da exposição Lectures, organizada pelo grupo, amplia as referências de Livro de Carne ao situá-lo entre as diversas possibilidades conceituais de um objeto concreto - o livro - e um abstrato - sua leitura. A partir dessa primeira abordagem, compara-se com outras situações de exibição do trabalho e demais experiências com o objeto livro na trajetória do artista.

PALAVRAS-CHAVE: Barrio; arte contemporânea; Grupo Cairn

\footnotetext{
* Viviane Matesco é Professora Associada da Universidade Federal Fluminense. Entre suas publicações, destacam-se Corpo, imagem e representação (Zahar, 2009), Em torno do corpo (PPGCA/UFF, 2016) e Experimentação e método (Museu do Ingá/Philae, 2018). E-mail: vivimatesco@gmail.com. Orcid: https://orcid.org/0000-0003-3528-9548
} 
ABSTRACT: The article provides an analysis of the Book of Meat (Livro de Carne), Arthur Barrio's work, focusing on the Parisian context where it was created. It examines the relationship between the artist and the Cairn Group, a cooperative of artists active in the 1970s, verifying the proximity of their ideas. The conjuncture of Lectures, an exhibition organized by the group, broadens the Book of Meat references by placing it among the conceptual possibilities of a concrete object the book - and an abstract one - its reading. From this first approach, it is compared with other exhibiting situations and experiences with the book object in the artist's trajectory.

KEYWORDS: Barrio; contemporary art; Cairn group

RESUMEN: El artículo desarrolla un análisis del Libro de Carne, obra del artista Arthur Barrio, focalizándose en el contexto parisino en el que fue creado. Indaga en la relación del artista con el Grupo Cairn, una cooperativa de artistas activos en la década de 1970, confirmando la proximidad entre sus ideas. La coyuntura de la exposición Lectures, organizada por el grupo, amplía las referencias del Libro de Carne al situarlo entre las diversas posibilidades conceptuales de un objeto concreto - el libro - y uno abstracto - su lectura. Desde este primer enfoque, se compara con otras situaciones de exhibición del trabajo y con otras experiencias del objeto libro en la trayectoria del artista.

PALABRAS CLAVE: Barrio; arte contemporáneo; Grupo Cairn

Como citar:

MATESCO, Viviane. Barrio e a cooperativa Cairn. Poiésis, Niterói, v. 20, n. 34, p. 357-374, jul./dez. 2019.

[https://doi.org/10.22409/poiesis.v20i34.38688]

Viviane Matesco, Barrio e a cooperativa Cairn. 


\section{Barrio e a cooperativa Cairn}

Barrio passou longas temporadas na Europa entre os anos de 1973 e 1985. Entre 1978 e 1983, participou ativamente do Grupo Cairn em Paris, momento importante de seu trabalho no qual os processos conceituais e a interação com um grupo de artistas franceses influenciaram sua poética. Entretanto, esse período foi muito pouco estudado e documentado, lapso que este artigo objetiva preencher. Analisaremos a presença de Barrio no jornal do grupo, focalizaremos a exposição Lectures e a realização do trabalho $L i$ vro de Carne na conjuntura parisiense.

Cairn é uma associação de produção e de distribuição de trabalhos artísticos criada em abril de 1976, cujo primeiro manifesto defendia uma vontade de independência em relação a todo grupo de pressão cultural. A cooperativa atuante entre os anos de 1976 e 1982 tinha como base uma galeria, o Espace Cairn, e um jornal, o CAIRN Journal $d^{\prime}$ une coopérative d'artistes ${ }^{2}$. O grupo era formado por artistas plásticos, dançarinos e poetas que desenvolviam trabalhos coletivos, tiragens de serigrafias, palestras e eventos interdisciplinares, além das atividades de galeria e jornal. Trimestral, a publicação era dirigida por Jean Dupanier e redigida por Roland Buraud, Bernard Crespin, Markus Kaufmann, Richard Pernollet, além de contar com a participação regular de Barrio, Hélène 
David, Dominique Haneuse, Jacqueline Larrieu. Compunha-se de artigos, entrevistas, fotografias, calendário e resenhas de exposições, projetos e intervenções de artistas que subvertiam o enquadramento convencional de um periódico.

Eco das discussões e ideias do grupo, as propostas são explicitadas no editorial do primeiro número, de janeiro de 1979 :

\section{Cairn não reivindica o poder, mas um poder e propõe, sem as impor, experiências múltiplas e eventualmente contraditórias, a recusa do discurso da vanguarda, de definições e de etiquetas. 0 grande e principal diferencial seria o fato de o grupo não se estruturar em uma estética coletiva que bloquearia um processo dinâmico. (CAIRN, 1979, p. 2)}

Também no primeiro número, uma pesquisa sobre as cooperativas atuantes na França e em Nova York fornece a dimensão da via alternativa e do trabalho coletivo para os artistas conceituais produzirem, exporem e divulgarem seus trabalhos. Nesse sentido, o jornal era uma extensão das atividades da cooperativa Cairn e atuava fazendo mediação de uma produção centrada mais em processos do que em obras de formato tradicional.
É justamente esse caráter transitivo que observamos nas obras de Barrio, tanto na galeria quanto no jornal do grupo. Entre 1978 e 1983, Barrio participa de inúmeras exposições no Espaço Cairn: em 1978, a individual Plenitude; em 1979, a mostra Lectures (leituras); em 1980, apresenta os trabalhos Movimento congelado, Marfim africano e Extensão; em 1981, A partida de tênis e Volto em 5. Ainda em 1981, realiza as ações Puídas... esgarçadas... rotas... e Situação nevoeiro ou os Ouvidos à distância. Em 1982, Barrio apresenta Minha cabeça está vazia / meus olhos estão cheios. Alguns desses trabalham implicam em fotografias, mas geralmente são objetos e instalações que supõem processos instáveis.

Ao cotejarmos essa produção com o material publicado no jornal, no entanto, observamos que $o$ artista lança mão de fotografias e textos de outros períodos e localidades. A exceção de Volto em 5 - ação em tonéis de madeira realizada por ocasião do evento Grand Adieu! Epargnons cela a notre pays -, documentado na edição de 1981, Barrio não registrou no jornal os trabalhos desenvolvidos na galeria do grupo. Dessa maneira, no número 2, de abril de 1979, justamente aquele

Viviane Matesco, Barrio e a cooperativa Cairn. 

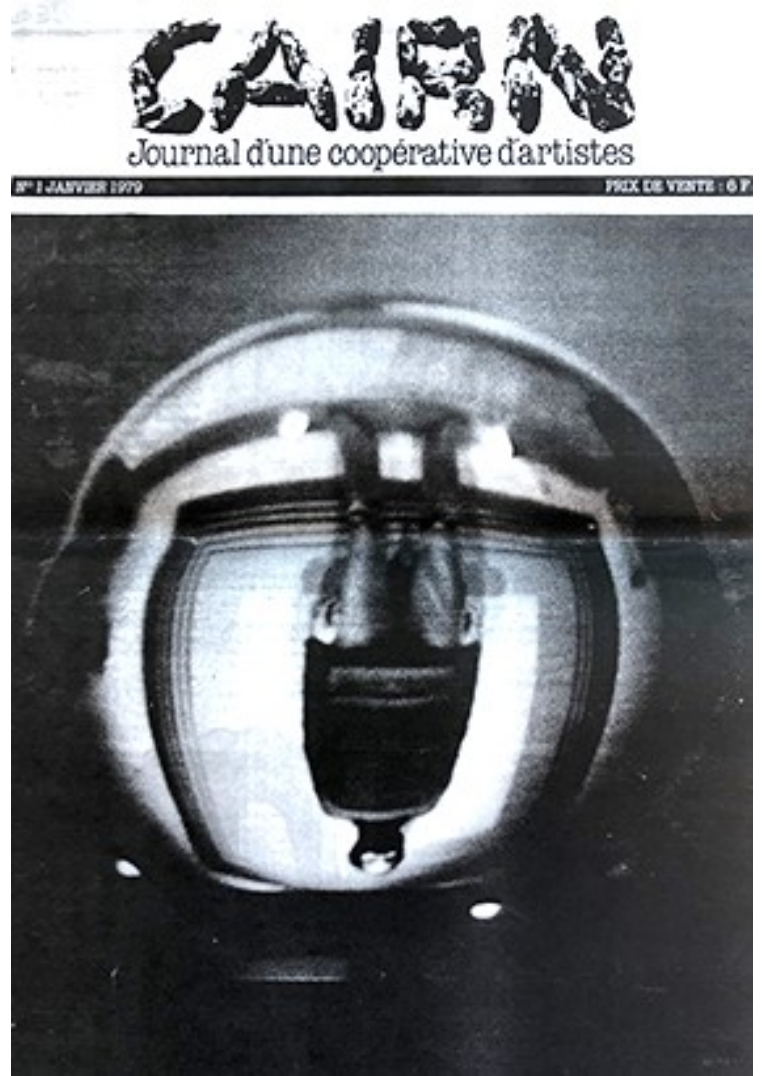

Fig. 1 - Capa do primeiro número do jornal Cairn, janeiro de 1979.

(Fonte: Biblioteca Kandinsky, Centro Georqes Pompidou, Paris) 
dedicado à exposição Lectures, apresenta a foto de Navalha Relógio (de 1970, RJ) e o texto Mitos Vadios, manifesto escrito por Barrio, Dinah Guimarães e Lauro Cavalcanti em 1978 em evento organizado por Ivald Granato em São Paulo. ${ }^{3}$

O número 4, do primeiro trimestre de 1980 , tem na capa o trabalho Áreas Sangrentas, realizado na cidade de Viana do Castelo (de 1975, Portugal) e também o trabalho metal /sebo, frio/calor (de 1974, Portugal); no número 5 , de maio de 1980 , foto e descrição do trabalho 4 movimentos, realizado em Mindelo (de 1974, Portugal).

Somente no número 6 de setembro de 1980, Barrio apresenta foto e descrição do trabalho D’Aprés lê dernier Portolano, realizado no Espaço Cairn.

A edição especial de dezembro de 1980, que anuncia evento Grand Dieu! Épargnos cela à notre pays, tem uma intervenção de Barrio, o projeto filme Lisez-vous, Voyezvous (Leia você, veja você), que consiste em uma fotografia de barco e a escrita peculiar do artista sugerindo uma situação envolvendo o mar.
Pelo número de fotografias e textos publicados no período entre 1979 e 1982, concluise que a participação de Barrio não é esporádica, estando o artista efetivamente engajado nas atividades da cooperativa. A ausência de uma cronologia e qualquer explicação das fotos de trabalhos anteriores nos números dos jornais evidencia a própria poética do artista, pois eles fazem parte de um fluxo de pensamento no qual antigos projetos podem ser atualizados. Também implicam processos efêmeros, apenas conhecidos mediante fotografias ou escritos do artista, seja em entrevistas ou nos Cadernoslivros.

Os diálogos estabelecidos entre Barrio e o grupo Cairn ficam mais claros a partir da análise do Livro de Carne, cuja datação implica esse processo não cronológico do artista. Dessa maneira, o projeto de Livro de Carne, assim como aquele de Rodapés de Carne (Nice, 1978), teria partido de ideia preliminar concebida no Rio de Janeiro em 1973, segundo escreve o artista no Livro Registro - Livro de Carne. (BARRIO, 1978) ${ }^{4}$

Viviane Matesco, Barrio e a cooperativa Cairn. 


\section{CAs \\ Journal dune coopérative dartistes}

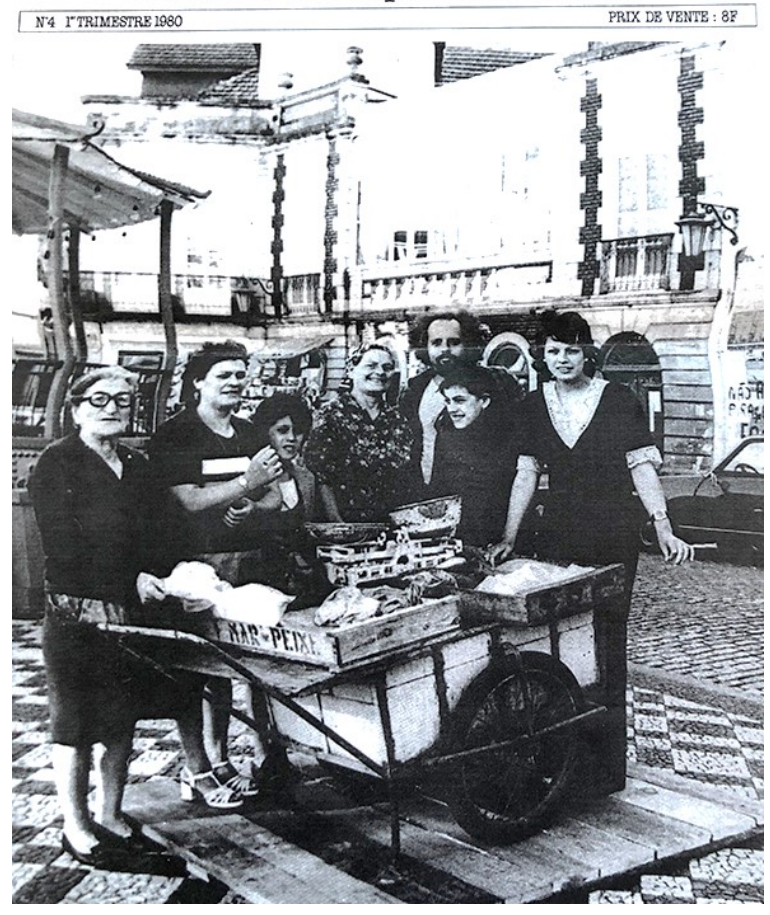

Fig. 2 - Capa do jornal Cairn, número 4, primeiro trimestre de 1980, com o trabalho de Barrio Áreas Sangrentas, realizado em 1975 na cidade de Viana do Castelo, Portugal. (Fonte: Biblioteca Kandinsky, Centro Georqes Pompidou, Paris) 

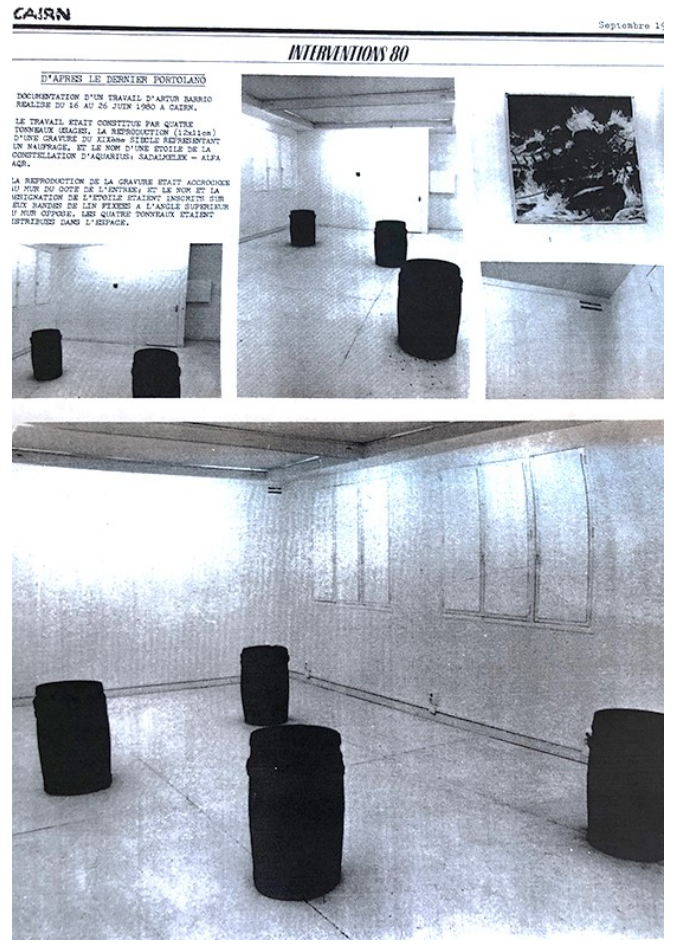

Fig. 3 - Jornal Cairn, número 6, setembro de 1980, foto e descrição do trabalho D'Aprés le dernier Portolano.

(Fonte: Biblioteca Kandinsky, Centro Georges Pompidou, Paris) 


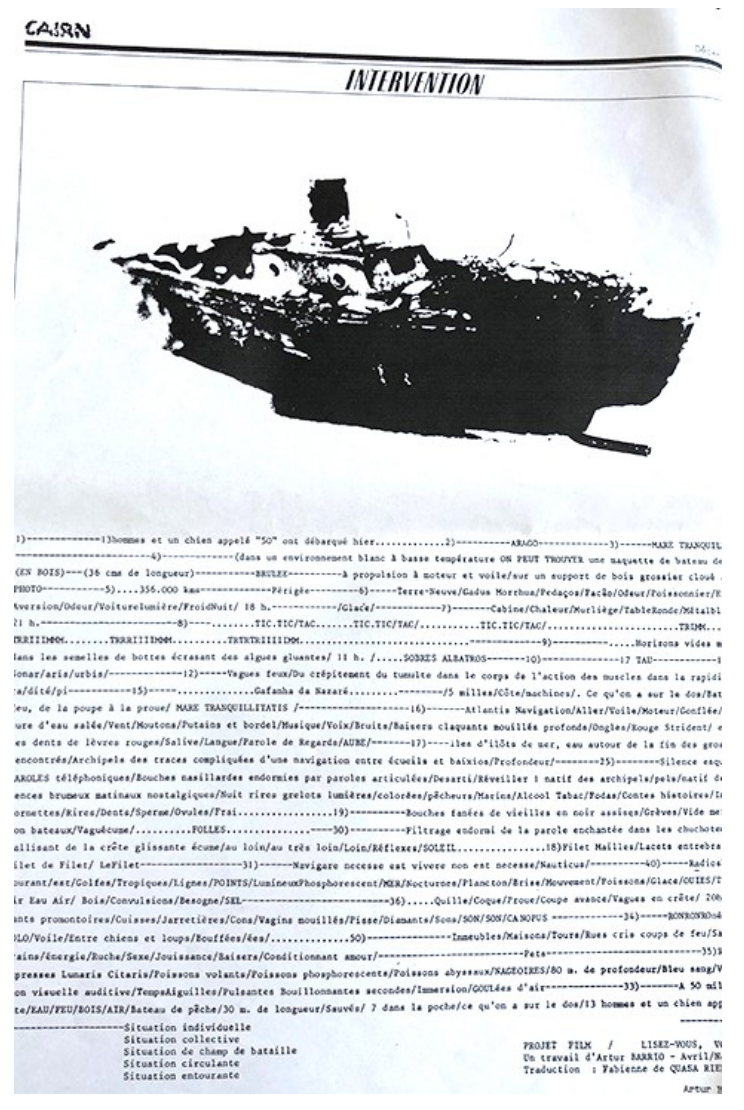

Fig. 4 - Jornal Cairn, edição especial, dezembro de 1980, projeto Lisez-vous, Voyezvous. (Fonte: Biblioteca Kandinsky, Centro Georges Pompidou, Paris) 
No entanto, a obra foi realizada e exposta em 1977, primeiro na coletiva de livros de artistas na Biblioteca Nacional da França e em seguida na Vitrine pour I'Art Actuel (Paris).

Nesse ano, tanto a Biblioteca Nacional da França quanto o Centro Georges Pompidou adquiriram livros/registros do artista, o que demonstra o quanto a questão do objeto livro é importante para o "livro de carne", fato também comprovado pela exposição dos $\mathrm{Ca}$ dernos Livros pertencentes à coleção Chateaubriand na Pinacoteca do Estado de São Paulo em 1978. Isso se torna ainda mais evidente quando analisamos a conjuntura da cooperativa Cairn, especificamente aquela da exposição Lectures, no Espace Cairn, em 1979, uma vez que podemos relacioná-lo a outras obras dos demais participantes do grupo.

No texto Porque leitura e não livros, Helena Davi partiu da constatação que a cooperativa poderia se apresentar sob a forma de uma biblioteca. Os membros do Cairn já estavam desenvolvendo anteriormente a forma de apresentação em cadernos, livros e álbuns para seus trabalhos. No entanto, trilhavam diversos caminhos como livros-objetos ou livros-testemunhas, imagens da cooperativa ou de uma experiência particular, livros sobre livros, ou ainda seu entorno, fabricação, conteúdo físico ou teórico. Como argumenta a curadora:

[...] 0 objeto livro implica leitura, então poderia focalizar no que se lê, quando se lê, como se lê ou ainda porque se lê e nenhuma dessas possibilidades deveria subsumir as demais totalizando o projeto. Desse modo, Lectures representa abordagens possíveis de certa entidade teórica nomeada "Iivro". Assim, o resultado foi uma mostra com múltiplas abordagens possíveis do livro e de sua leitura; coabitavam e se complementavam sem se excluírem. Conhecendo o conjunto de questões colocadas pela Cairn, seria possível ao espectador jogar 0 jogo: pesquisar que trabalho traria respostas, quais as combinações possíveis, procurar relações em uma palavra ou ainda construir uma rede semântica que relacionasse todos eles. Não seria absurdo estabelecer um paralelismo entre a estrutura de uma biblioteca e a estrutura da cooperativa Cairn. Uma biblioteca é uma estrutura que em relação aos seus utilizadores e objetos, apresenta três aspectos distintos, mas não excludentes: um espaço de arrumação de objetos, um espaço de classificação de objetos contido dentro do anterior, e um espaço de arrumação aos utilizadores da biblioteca por intermédio do espaço de classificação contidos den-

Viviane Matesco, Barrio e a cooperativa Cairn. 


\section{VITRINE pour l'art actuel}

\section{A. A. BARRIO LIVRE DE VIANDE Mercredi le 25 Avril}

51 rue quincampoix, 75004 paris, tél. 271.32 .98 mardi - samedi, $12: 20$ heures

Fig. 5 - Convite da exposição Livro de Carne na Vitrine pour l'Art Actuel, 1977.

(Fonte: Biblioteca Kandinsky, Centro Georges Pompidou, Paris) 
A. BARRIO R. BURAUD CHCESCHU B. CRESPIN H. DAVID J. ET J. DUPANIER D. HANEUSE I. LARRIEU A.C. LEVRAT J.C.MARQUETTE R. PERNOLLET C. SHAFER M. SILVERI J.SIROT

\section{"Lectures"}

\section{EXPOSITION COLLECTIVE}

- CAIRN A LIVRE OUVERT: DU SAMEDI 24 MARS AU SAMEDI 28 AVRIL 79 Des livres à lire, des livres à regarder, des livres à toucher . .

L'environnement est une bibliothèque, il tient compte de "nos» différences, t les travaux individuels forment un dictionnaire de Cairn, éclaté dans le temps et dans l'espace.

Au visiteur d'accepter le jeu ou de le refuser, de se mettre ou non à lire, de manipuler tous ces livres, de les faire "exister", dans un espace conçu pour un séjour paisible où l'on peut se promener sans hâte.

- RENCONTRE : MARDI 27 MARS 79 A 20 HEURES

Deux approches: Sylvaine Letellier, danseuse; Jacques Sirot, plasticien. Film vidéo, diapositives

CAIRN 151, FAUBOURG ST ANTOINE 75011 PARIS TEL. $3070848 / 3070888$

Fig. 6 - Convite da Exposição Lectures no Espaço Cairn.

(Fonte: Biblioteca Kandinsky, Centro Georges Pompidou, Paris) 
tro do anterior e um espaço de leitura: transferên-

cia de informações dos objetos contidos no espaço arrumação aos utilizadores da biblioteca por intermédio do espaço de classificação. (DAVID, 1979, p. 11; tradução livre)

Com a participação de quinze artistas ${ }^{5}$, a coletiva objetivava a visualização das múltiplas relações entre um objeto concreto - um livro - e abstrato, sua leitura. As relações obtidas por intermédio de transformações pontuais como translações e rotações, analogia, simetria, espelhamento e similitude criavam uma tessitura no interior de cada trabalho e entre eles. Todos desenvolveram propostas com situações de variação, escolhas e interação, como, por exemplo, aquela de Roland Burruad de refletir sobre a questão da encadernação replicando seus sistemas em suas próprias páginas; também Choeschu criou um ambiente onde o leitor podia entrar e ler as páginas de seda que fechavam o espaço; já Bernard Crespin explorava a metáfora da sensibilidade da leitura mediante aquela do papel e da película fotográfica. Jean Dupanier desenvolveu um livro fractal, realização de objetos flexíveis quanto às dimensões colocados em espaços estranhos por intermé- dio de jogo de espelhos. Gwylène Gallimard Dominique Haneuse Jaqqueline Larrieu, Jean-Claude Marquette Richard Pernollet, Camille Shafer, Massimo Silver, Jacques Sirot e a própria Helene David desenvolveram livros que supõem situações de variações, escolhas, interações. (DAVID, 1979, p. 10)

Livro de Carne assume feição mais complexa a partir desse contexto, pois está imerso em uma rede de possibilidades conceituais construída pela interação com as demais "obras". O trabalho relaciona o gesto do açougueiro que fatia a carne em bifes e a reunião desses elementos em um livro. A superposição remete a um livro por diversos aspectos: do ponto de vista espacial, pela relação entre as fatias; do ponto de vista temporal, pelo escurecimento mais rápido nas fatias superiores, aquelas da cobertura do livro; do ponto de vista gráfico, pelos desenhos das fibras musculares configurando o texto do livro e, finalmente, do ponto de vista orgânico, por sua textura, fibras musculares / fibras do papel e por sua conservação, carne/papel, matérias perecíveis em intervalos de tempo diferentes. (DAVID, 1979, p. 11) 


\section{POURQVOI "LECTURES" ET NON "LIVRES"?}

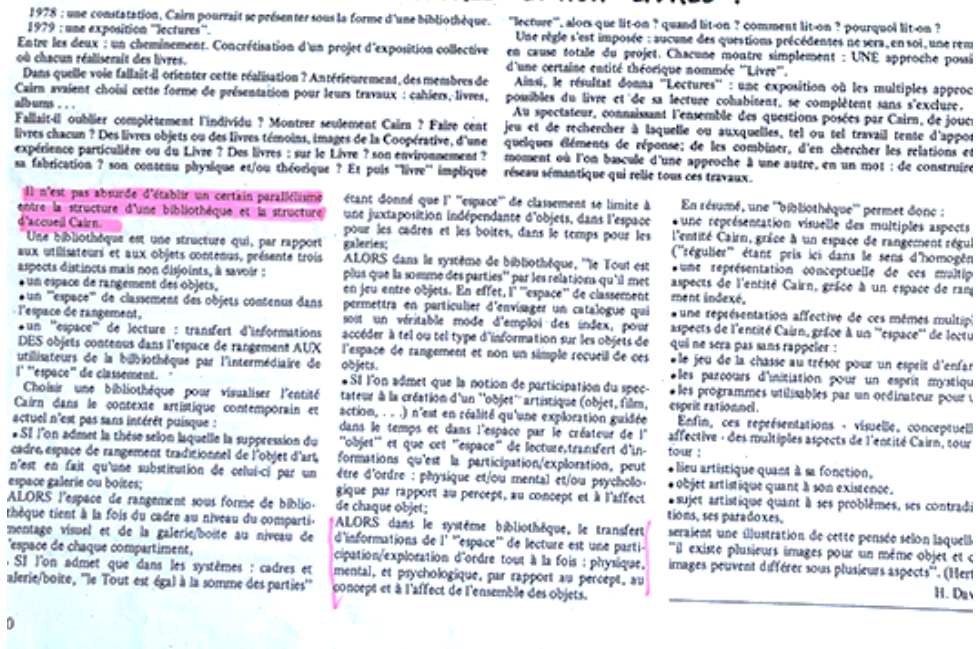

Fig. 7 - Texto de Helena Davi reproduzido no Jornal Cairn, número 2, de abril de 1979. (Fonte: Biblioteca Kandinsky, Centro Georges Pompidou, Paris) 
É importante ressaltar que a deterioração da matéria é apenas um dos aspectos colocados em jogo, pois a exposição focaliza as relações e inúmeros registros do objeto livro. É interessante observarmos como a analogia como o gesto do açougueiro e a pluralidade de abordagens do Livro de Carne é utilizada tanto pela curadora em seu texto quanto pelo próprio Barrio no Livro Registro - Livro de Carne, de 1979, o que demonstra a proximidade dos processos de elaboração do trabalho e aquele do contexto da exposição.

A multiplicidade de leituras postas em questão na mostra Lectures permite que as representações visuais, conceituais e afetivas sejam colocadas como um tour a partir de uma metáfora do funcionamento da cooperativa: lugar artístico quanto à sua função, objeto artístico quanto à sua existência, sujeito artístico quanto aos seus problemas, suas contradições e seus paradoxos, ilustração do pensamento segundo o qual existem várias imagens para um mesmo objeto e elas podem diferir sob diversos aspectos.

A subversão da racionalidade do livro e a impotência da leitura é o ponto que gostaríamos de ressaltar no trabalho Livro de Carne: a questão do fluxo inconcluso. O caráter de diário dos Cadernoslivros relaciona-se àquele do explorador-cientista que anota suas experiências para reter as impressões de um momento transitório. A maneira como Barrio realiza essas anotações, no entanto, inviabiliza qualquer rigor científico. Nos $\mathrm{Ca}$ dernoslivros não há a ideia de planejamento, um antes para executar depois, ou a sistematização de projetos realizados. Ao lermos as anotações não sabemos exatamente o momento em que foram feitas, pois abrangem um período longo no qual as referências aos trabalhos se misturam, como se estivessem juntas em um mesmo processo psíquico atemporal. A utilização de objetos, fotografias, desenhos, escritas desconectadas, bem como a mistura de francês e português enfatizam o sentido de fluxo de pensamento. As palavras, os riscos, as imagens e objetos deflagram um processo psíquico que associa a memória desordenada das ações, como se fossem traços da experiência vivida. É interessante comparamos a impossibilidade de leitura linear dos Cadernoslivros de Barrio como processo equivalente, uma vez que neles o "encadeamento sucessivo das palavras perde hegemonia para o riscado, para a linha borrada e caótica, o que impõe a relação entre texto e imagem". 6 No CadernoLivro de 1978 (BARRIO, 1978), no qual faz referência 
à historiadora Daw Ades, aos movimentos dadaísta e surrealista, Barrio escreve que a desorientação do espectador constitui um passo em direção à destruição das maneiras convencionais de apreender o mundo e de manipular as próprias experiências, de acordo com padrões preconcebidos.

A oposição entre objeto e situação gerou controvérsias por ocasião da mostra Barrio: Registros de trabalho, na Funarte em 1981 (BARRIO, 1981); a crítica questionava o caráter independente dos registros, considerando uma institucionalização se comparadas à efemeridade das Situações. ${ }^{7}$ Efetivamente não se pode tomar os Cadernoslivros como registros, mas não se pode negar toda uma produção do artista voltada para essa questão, desde sua materialidade à sua função ou disfunção a partir dos escritos. A discussão se eles seriam obras autônomas das Situações é totalmente infrutífera, pois nada em Barrio é completo, autônomo ou passível de ser absorvido por uma sistematização. É justamente o caráter intraduzível que aproxima o Livro de Carne dos Cadernoslivros. A conjuntura parisiense na qual o livro foi concebido, as relações com o grupo Cairn, sua exposição a partir da questão da leitura, biblioteca e livro de artista afirmam especificidade do trabalho frente às intervenções/situações.

Quando examinamos a compreensão do $L i$ vro de Carne a partir dessa conjuntura parisiense e a comparamos com outros momentos nos quais a "obra" foi exposta fica claro o distanciamento. Observa-se, por essa recepção, como o trabalho passa a ser deslocado do universo do objeto livro para ser enfocado apenas pela relação com os processos orgânicos das Situações. Isso pode ser evidenciado em duas mostras bem distantes cronologicamente: a Sala Especial "A arte e seus materiais: atitudes contemporâneas", de 1985, e a 24a Bienal de São Paulo, de 1998. Na primeira, a escolha do trabalho deveu-se à própria opção curatorial, mas a relação ajuda a solidificar visualidade do Livro de Carne pelo viés do material. Na 24a Bienal, o trabalho é apresentado isolado em uma vitrine, como uma relíquia associada à temática da antropofagia e, portanto, seu sentido também é colocado na redoma da simbologia da matéria. Compreender o trabalho de Barrio apenas pela poética da matéria é emprestar à substância uma estabilidade alheia ao universo do artista. Em Barrio, a ausência de representação definitiva diante do mundo provoca um deslocamento,

Viviane Matesco, Barrio e a cooperativa Cairn. 
abismo entre o que é apresentado e compreendido.

Não quisemos aqui negar a importância da poética da matéria no Livro de Carne, importante suficientemente para o artista ter desenvolvido no mesmo período os Rodapés de Carne (1978, Paris e Nice) e, mais tarde, em 1994, Cancela de Carne (Museu do Açude, Rio de Janeiro). Objetivou-se, no entanto, ampliar universo de pesquisa e de crítica do trabalho, deslocando-o de sua interpretação habitual para a conjuntura do seu período parisiense e de suas relações com Grupo Cairn. Procuramos demonstrar como a mesma obra assume feições diferentes a partir não só de uma relação espacial expositiva, mas, sobretudo, frente a contextos artísticos diferentes.

\section{Notas}

\footnotetext{
${ }^{1}$ Este artigo parte de uma comunicação realizada no Comitê Brasileiro de História da Arte em Brasília, em 2012.

2 Tanto o Espaço quanto o Jornal eram sediados no mesmo endereço na rua Faubourg Saint-Antoine, 151 no $11 \mathrm{eme}$ arrondissement.

${ }^{3}$ Em evento organizado por Ivald Granato em São Paulo. Ao cotejarmos o teor das propostas do grupo
}

com aquelas desse manifesto, concluímos que existia total comunhão de ideias relativas à questão do processo artístico.

${ }^{4}$ Coleção Chateuabriand/MAM-RJ: "em 10 de fevereiro, às 19h, começarei o projeto Rodapés de Carne, 19731978, em um local, Garage 103" e, em seguida, descreve a ação.

${ }^{5}$ Barrio, Jean Dupanier, Gwylène Gallimard, Dominique Haneuse, Jaqqueline Larrieu, Jean-Claude Marquette, Richard Pernollet, Camille Shafer, Massimo Silver, Jacques Sirot, Roland Burruad, Bernard Crespin, Choeschu e a própria curadora Hélène Davi.

6 “A realização de projetos de instalações que implicam a escrita em espaços expositivos também reafirma uma não-lineraridade e uma fluência por entre as matérias do mundo, processamento e produção virtual/real de sensorialidade". A esse respeito, ver BASBAUM, Ricardo. Dentro D’Água. In CANONGIA, Ligia (Org.). Artur Barrio. Rio de Janeiro: Modo, 2002, p. 228-229.

7 Nas palavras de Frederico Morais: “apesar da ressalva 373 do artista de que o registro não é um documento, é ele que, efetivamente existe, pois o trabalho original desapareceu. $\mathrm{E}$ a foto estetiza o que originalmente tinha caráter visceral, agressivo, nojento, amortece aquilo que trazia originalmente uma carga crítica ou contestatória que realmente incomodava. A foto como registro é uma forma de pasteurização crítica, de facilitação do consumo. É o modo encontrado pelo artista de trazer de volta ao museu ou galeria o seu trabalho e, assim, recuperar algumas das regalias contra as quais lutou e que explicam o próprio caráter contundente de sua criação. Mas trazer de volta aos museus ou galerias suas obras, através do recurso do registro fotográfico, é inserir-se novamente na tradição da arte, no continuum da história da arte. Ver MORAIS, Frederico. Barrio, dentro da tradição. O Globo, Rio de Janeiro, 15 jul. 1981; COUTINHO, Wilson. Os registros de Barrio. Jornal do Brasil, Rio de Janeiro, 1981. 


\section{Referências}

BARRIO. Sem título (CadernoLivro), 1978. nanquim, hidrográfica, fotografia, metal e fita adesiva sobre papel. Coleção Gilberto Chateaubriand, Museu de Arte Moderna do Rio de Janeiro (ID 105/17583).

BARRIO. Livro Registro - Livro de Carne, de 1979, Coleção Chateaubriand/Museu de Arte Moderna do Rio de Janeiro. Acervo do Museu de Arte Moderna, Rio de Janeiro.

CANONGIA, Ligia (Org.). Artur Barrio. Rio de Janeiro: Modo, 2002.

Catálogos:

FUNARTE. Barrio: Registros de trabalho. Rio de Janeiro: Funarte, 1981.

FUNARTE. Sala Especial do $8^{\circ}$ Salão Nacional de Artes Plásticas, Rio de Janeiro: Funarte, 1985.

FUNDAÇÃO BIENAL DE SÃO PAULO. 24a Bienal de São Paulo. São Paulo: Fundação Bienal, 1998.

FRAC PROVENCE. Artur Barrio Imprope à la consommation humaine. Marseille: Frac Provence/Isthme Éditions, 2005.

CAIRN. Grand Dieu! Épargnons cela à notre pays. Paris: Cairn, 1981.
Periódicos:

CAIRN Journal $d^{\prime}$ une coopérative d'artistes. Paris: CAIRN, n. 1 Janvier 1979. (Biblioteca Kandinsky - Centro Georges Pompidou, Paris. (BK-CGP)

CAIRN Journal d' une coopérative d'artistes. Paris: CAIRN, n. 2 Avril 1979. (BK-CGP)

CAIRN Journal d' une coopérative d'artistes. Paris: CAIRN, n. 4 Ie / 1980. (BK-CGP)

CAIRN Journal $d^{\prime}$ une coopérative d'artistes. Paris: CAIRN, n. 5- 2e/ 1980. (BK-CGP)

CAIRN Journal d' une coopérative d'artistes. Paris: CAIRN, n. 6- 3e / 1980. (BK-CGP)

CAIRN Journal $d^{\prime}$ une coopérative d'artistes. Paris: CAIRN, n. 7- 3e/1980. (BK-CGP)

CAIRN Journal $d^{\prime}$ une coopérative d'artistes. Paris: CAIRN, n. 8-1e/1981. (BK-CGP)

COUTINHO, Wilson. Os registros de Barrio. Jornal do Brasil, Rio de Janeiro, 1981. (Centro de Documentação, Museu de Arte Moderna, Rio de Janeiro)

MORAIS, Frederico. Barrio, dentro da tradição. O Globo, Rio de Janeiro, 15 jul. 1981. (Centro de Documentação, Museu de Arte Moderna, Rio de Janeiro) 